\author{
Naoya Wada ${ }^{\mathrm{a}}$, Yoshiharu Azuma ${ }^{\mathrm{a}}$, Mahoto Takeda ${ }^{\mathrm{a}}$, Zenji Hiroi ${ }^{\mathrm{b}}$ \\ ${ }^{a}$ Department of Materials Engineering (SEISAN), Yokohama National University, Japan \\ ${ }^{\mathrm{b}}$ Institute for Solid State Physics, University of Tokyo, Japan
}

\title{
The relationship between the microstructure and the magnetic properties of nano-scale magnetic particles in a $\mathrm{Cu}-\mathrm{Fe}-\mathrm{Co}$ ternary alloy
}

\begin{abstract}
The relationship between the microstructures and the properties of nano-scale $\mathrm{Fe}-\mathrm{Co}$ magnetic particles formed in a copper alloy was investigated. Several structural aspects and physical properties of $\mathrm{Fe}-\mathrm{Co}$ precipitates were investigated simultaneously using transmission electron microscopy, high resolution transmission electron microscopy, and superconducting quantum interference device magnetometry. The microstructure and magnetic properties of precipitates comprising both $\mathrm{Fe}$ and $\mathrm{Co}$ atoms evolved with isothermal annealing at $873 \mathrm{~K}$. We found that the evolution of small coherent precipitates obeys the Ostwald ripening law; however, the coarsening rate of the particles increased after coherent particles transformed into incoherent precipitates. The coercive force varied, correlating with the evolution of precipitates.
\end{abstract}

Keywords: $\mathrm{Cu}-\mathrm{Fe}-\mathrm{Co}$; Precipitation; Nano-scale magnetic particles; TEM; HRTEM

\section{Introduction}

In recent years, granular magnetic materials, in which magnetic particles are embedded in metal matrices, have been studied intensely because of their widespread application for ultra-compact magnetic storage devices. Besides their practical applications, granular magnetic materials are of fundamental interest for studying physical phenomena such as spin-/cluster-glass behavior, superparamagnetism, and the kinetics of coarsening and precipitation. The discovery of giant magneto-resistance (GMR) by Berkowitz [1] in an immiscible binary $\mathrm{Cu}-\mathrm{Co}$ alloy system has further stimulated attention towards these materials especially in the last decade. A number of studies have been made on nano-scale magnetic precipitates in copper alloys, using neutron and Xray diffraction, transmission electron microscopy (TEM), Mössbauer spectroscopy, superconducting quantum interference device (SQUID) magnetometry, and other techniques. These studies have demonstrated that the magnetic properties of metallic particles are sensitive to their microstructure including their sizes, shapes, and composition.

According to the $\mathrm{Cu}-\mathrm{Fe}$ phase diagram, large $\mathrm{Fe}$-rich precipitates in $\mathrm{Cu}-\mathrm{Fe}$ alloys are expected to have the body-centered cubic lattice (bcc) structure below a temperature of $1130 \mathrm{~K}$. However, small Fe particles keep the face-centered cubic lattice (fcc) structure even below $1130 \mathrm{~K}$ in the initial stage of precipitation, retaining their coherency to the $\mathrm{Cu}$ matrix. Furthermore, a lattice modulation similar to pre-martensite or some type of diffusionless transformation has also been reported [2]. In this context, Kubo et al. claimed that $\mathrm{Fe}$ precipitates which formed at the edges of thin foils transformed without plastic deformation [3], although Abraham concluded that fcc precipitates do not transform into the bcc phase on simple cooling [4]. In a TEM study conducted by the present authors, bcc Fe precipitates with layered domains, which are similar to those reported by Kubo, were observed during isothermal annealing without plastic deformation. It was confirmed by high resolution transmission electron microscope (HRTEM) that layered domains with alternating light and dark contrast in $\mathrm{Fe}$ precipitates were due to a twin-like structure. These characteristic features of nano-scale $\mathrm{Cu}-$ Fe particles have not been seen explicitly in other alloy systems such as $\mathrm{Cu}-\mathrm{Co}$, although a linear alignment of coherent Co precipitates without any external stress field have been observed by TEM [5-7]. Relatively little is known about the microstructure of $\mathrm{Cu}-\mathrm{Fe}-\mathrm{Co}$ alloys as compared with $\mathrm{Cu}-\mathrm{Fe}$ or $\mathrm{Cu}-\mathrm{Co}$ alloys [8]. The different trends of precipitation occurring in $\mathrm{Cu}-\mathrm{Fe}$ and $\mathrm{Cu}-\mathrm{Co}$ alloys also suggest that it is of interest to investigate precipitation in a ternary $\mathrm{Cu}-\mathrm{Fe}-\mathrm{Co}$ alloy system. The present study aimed to clarify the precipitation process and magnetic properties appearing in $\mathrm{Cu}-\mathrm{Fe}-\mathrm{Co}$ alloys, combining TEM observations with measurements of magnetic properties by SQUID magnetometry.

\section{Experimental}

The specimens of $\mathrm{Cu}-\mathrm{Fe}-\mathrm{Co}$ alloy investigated in this study were prepared from pure metals by arc melting. We prepared four alloys with differing solute compositions and $\mathrm{Fe}$ : $\mathrm{Co}$ ratios as listed in Table 1. After arc melting, the ingots were cold rolled to a thickness of approximately $130 \mu \mathrm{m}$, with intermediate annealing at $923 \mathrm{~K}$ in a salt bath. In order to obtain the microstructure in solid solution, a solution-treatment was carried out at $1273 \mathrm{~K}$ in evacuated quartz capsules using an infrared furnace, following by quenching into ice water $(273 \mathrm{~K})$. The specimens were then annealed at $873 \mathrm{~K}$ and $973 \mathrm{~K}$ for various periods up to $10000 \mathrm{~min}$, and subsequently quenched into ice water. 
N. Wada et al.: The relationship between the microstructure and the magnetic properties of nano-scale magnetic particles

Table 1. The chemical compositions of the alloy specimens.

\begin{tabular}{|l|c|c|c|c|c|}
\hline \multirow{2}{*}{} & \multicolumn{5}{|c|}{ composition (at.\%) } \\
\cline { 2 - 6 } & $\mathrm{Cu}$ & $\mathrm{Fe}$ & $\mathrm{Co}$ & $\begin{array}{c}\text { Percentage } \\
\text { of solute }\end{array}$ & Fe: Co \\
\hline $\mathrm{Cu}-0.8$ at.\% Fe-0.2 at.\% Co & 99 & 0.8 & 0.2 & $1 \%$ & $4: 1$ \\
$\mathrm{Cu}-0.6$ at.\% Fe-0.4 at.\% Co & 99 & 0.6 & 0.4 & $1 \%$ & $3: 2$ \\
$\mathrm{Cu}-2.4$ at.\% Fe-0.6 at.\% Co & 97 & 2.4 & 0.6 & $3 \%$ & $4: 1$ \\
$\mathrm{Cu}-1.8$ at.\% Fe-1.2 at.\% Co & 97 & 1.8 & 1.2 & $3 \%$ & $3: 2$ \\
\hline
\end{tabular}

Bright field TEM observations were performed to confirm the microstructures of specimens for each stage of the annealing process. The final specimens for TEM observations were prepared by conventional electro-polishing in a solution of methanol and nitric acid, and observed using a HITACHI H-800 transmission electron microscope operated at $200 \mathrm{kV}$ for bright-field image observations and a $300 \mathrm{kV}$ JEOL JEM-3010F field emission transmission electron microscope for high-resolution imaging. All TEM images were taken along the [001] zone axis of the $\mathrm{Cu}$ matrix. The magnetization measurements were conducted with a Quantum Design MPMS SQUID magnetometer. Complete hysteresis loop (M-H curves) were obtained with magnetic field, $-4 \mathrm{~T} \sim 4 \mathrm{~T}$.

\section{Results and discussion}

\subsection{The microstructure of $\mathrm{Cu}-\mathrm{Fe}-\mathrm{Co}$ alloys}

We first examined the evolution of the microstructures of four specimens after isothermal annealing at $873 \mathrm{~K}$. Figure 1 shows bright field TEM images of the microstructures of $\mathrm{Cu}-2.4$ at. $\% \mathrm{Fe}-0.6$ at.\% $\mathrm{Co}$ aged for (a) $0 \mathrm{~min}$, (b) $1000 \mathrm{~min}$, (c) $2000 \mathrm{~min}$, and (d) $10000 \mathrm{~min}$, respectively. As shown in Fig. 1a, immediately after the solution-treatment, no precipitates were visible. It is possible that precipitates were present but were too small to be seen in the instrument we used, but neither streaks nor extra spots were observed in electron diffraction patterns. Figure 1b shows the precipitates in a specimen annealed for $1000 \mathrm{~min}$. The precipitates were about $15 \mathrm{~nm}$ in size and were randomly distributed throughout the $\mathrm{Cu}$ matrix, as is often seen in other alloys such as $\mathrm{Cu}-\mathrm{Cr}$. The electron microscope contrast seems consistent with coherent, spherical precipitates in this early stage of precipitation. The equilibrium structure of bulk Fe-Co, according to the equilibrium phase diagram, is bcc (A2), B2 or hexagonal close-packed structure (hcp). This was confirmed by electron diffraction, which showed that the crystal structure of the precipitates was fcc, as inherited from $\mathrm{Cu}$ matrix. After annealing for $2000 \mathrm{~min}$, the coherent precipitates, now about $20 \mathrm{~nm}$ in size, were linearly aligned in pairs along the $\langle 100\rangle$ directions of the $\mathrm{Cu}$ matrix as seen in Fig. 1c. This feature was also found in our previous study of Co precipitates in a $\mathrm{Cu}$ matrix [6]. After annealing for $5000 \mathrm{~min}$, large irregularshaped precipitates, which were tangled with interfacial dislocations, appeared among spherical coherent precipitates. The interfacial dislocations indicate that the large precipitates had lost their coherency to the $\mathrm{Cu}$ matrix and had become incoherent, as seen in Fig. 1d.

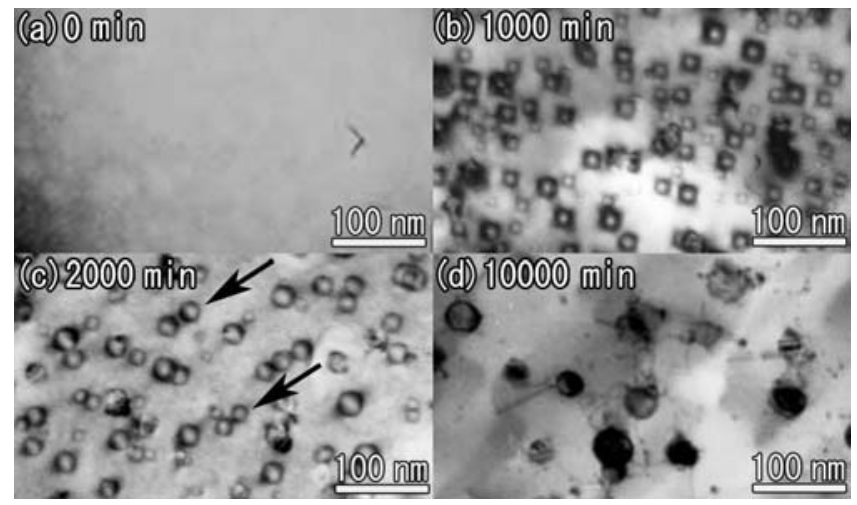

Fig. 1. Bright-field images of $\mathrm{Cu}-2.4$ at.\% Fe-0.6 at.\% $\mathrm{Co}$ aged at $873 \mathrm{~K}$ for (a) $0 \mathrm{~min}$, (b) $1000 \mathrm{~min}$, (c) $2000 \mathrm{~min}$, and (d) $10000 \mathrm{~min}$. The arrows in (c) indicate of a pair linearly arranged Fe particles

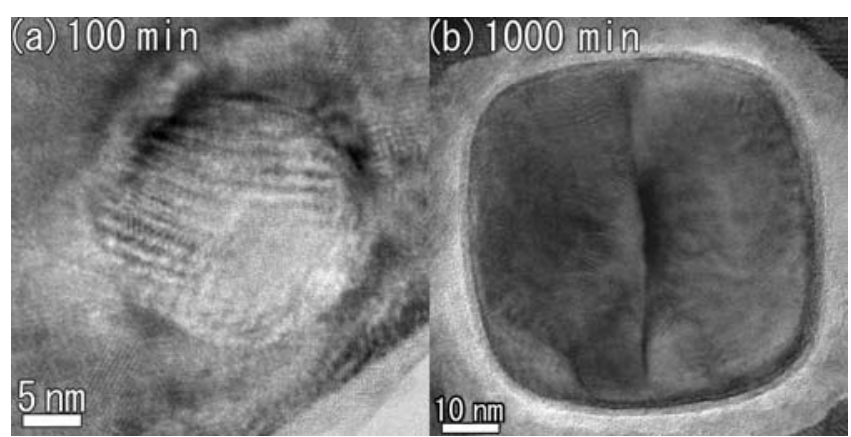

Fig. 2. High-resolution TEM images of $\mathrm{Cu}-1.8$ at.\% $\mathrm{Fe}-1.2$ at.\% Co aged at $973 \mathrm{~K}$ for (a) $100 \mathrm{~min}$, and (b) $1000 \mathrm{~min}$.

Since it is difficult to investigate the detailed shapes of particles by conventional TEM due to dynamical diffraction effects, we conducted HRTEM observations. Figure 2 shows HRTEM images of $\mathrm{Cu}-1.8$ at.\% Fe-1.2 at.\% Co annealed at $973 \mathrm{~K}$ for (a) $100 \mathrm{~min}$ and (b) $1000 \mathrm{~min}$. At the earlier stage of the annealing process, particles had diameters of $10-15 \mathrm{~nm}$ and were spherical in shape, as shown in Fig. 2a. After annealing for $5000 \mathrm{~min}$, cubic precipitates with nearly (100) planes and round corners were observed. Similar-shaped coherent precipitates have been observed in $\mathrm{Cu}-\mathrm{Co}$ [9]. It seems that coherent precipitates are initially spherical, and gradually change into a cubic shape with round corners as they grow. Onaka et al. interpreted the transition from spherical to cubic shape, by taking the strain field energy and interfacial energy into consideration [10].

In order to examine the coarsening processes of $\mathrm{Cu}-\mathrm{Fe}-$ $\mathrm{Co}$, we measured the volume fraction, growth rate and size 
N. Wada et al.: The relationship between the microstructure and the magnetic properties of nano-scale magnetic particles

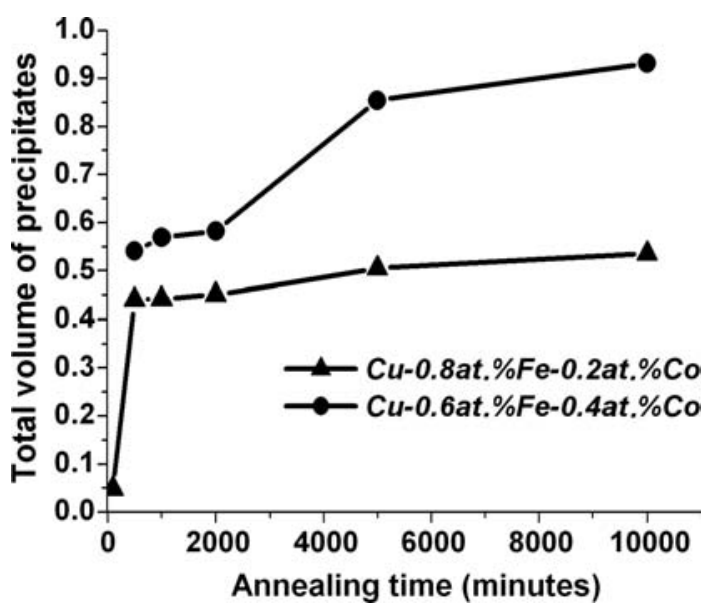

Fig. 3. Total volume of $\mathrm{Fe}-\mathrm{Co}$ precipitates formed in a $\mathrm{Cu}$ matrix of $\mathrm{Cu}-0.8$ at. $\% \mathrm{Fe}-0.2$ at. $\% \mathrm{Co}$ and $\mathrm{Cu}-0.6$ at. $\% \mathrm{Fe}-0.4$ at. $\% \mathrm{Co}$.

distribution of the precipitates. Figure 3 shows the change of the volume fraction of $\mathrm{Fe}-\mathrm{Co}$ precipitates with annealing time for $\mathrm{Cu}-0.8$ at.\% $\mathrm{Fe}-0.2$ at.\% $\mathrm{Co}$ and $\mathrm{Cu}-0.6$ at.\% $\mathrm{Fe}-$ 0.4 at.\% Co. For both materials, the volume of the precipitates initially increased with annealing time up to $500 \mathrm{~min}$, and then remained constant between $500 \mathrm{~min}$ and $2000 \mathrm{~min}$. Beyond an annealing time of $5000 \mathrm{~min}$, the total volume of precipitates for each composition seems nearly saturated. Figure 4 shows curves of the mean size of the precipitates vs. the one-third power of annealing time for (a) $\mathrm{Cu}$ 0.8 at. $\% \mathrm{Fe}-0.2$ at.\% $\mathrm{Co}$, (b) $\mathrm{Cu}-0.6$ at.\% Fe-0.4 at.\% Co, (c) $\mathrm{Cu}-2.4$ at. $\% \mathrm{Fe}-0.6$ at. $\% \mathrm{Co}$, and (d) $\mathrm{Cu}-1.8$ at. $\% \mathrm{Fe}-$ 1.2 at. $\%$ Co. For the first $2000 \mathrm{~min}$, the particle size in each case is proportional to the one-third power of the annealing time. However for annealing times greater than $5000 \mathrm{~min}$, all of the curves deviate upwards from a straight line. It has been reported that the coarsening process of $\mathrm{Cu}-\mathrm{Fe}$ and $\mathrm{Cu}-\mathrm{Co}$ alloys is subject to the theory of Ostwald ripening $[6,11,12]$. According to this theory, the following conditions should hold: first, the shape of precipitates remains essentially unchanged; second, the volume fraction of precipitates remains constant; and third, the particle size is proportional to the one-third power of the annealing time. The present TEM observations confirm that all of these conditions are met at annealing times $<2000 \mathrm{~min}$. This indicates that the growth of $\mathrm{Fe}-\mathrm{Co}$ precipitates in a $\mathrm{Cu}$ matrix is essentially similar to Ostwald ripening in the initial stage of annealing [16]. At annealing times longer than $5000 \mathrm{~min}$, both the total volume of precipitates and their mean sizes are larger than those predicted by Ostwald ripening theory. Little information is available on the relationship between the lattice coherency and growth rate of particle. However it is reported experimentally that loss of coherency leads to an increase in the growth rate of particles in $\mathrm{Cu}-\mathrm{Co}$ and Al-Sc alloys [6, 13]. The equilibrium structure of large $\mathrm{Fe}-\mathrm{Co}$ precipitates is bcc. A structural transformation from fcc to bcc is therefore expected to occur when the precipitates reach a size large enough to overcome the constraint from the $\mathrm{Cu}$ matrix. Kuwano et al. reported that $\mathrm{Fe}-\mathrm{Co}$ precipitates transformed martensitically from fcc into bcc even with no plastic deformation under an annealing condition similar to that employed in this study [14]. As mentioned above, the present TEM observations confirmed that large precipitates accompanied by interfacial dislocations appeared among coherent precipitates after a long ageing time, Fig. 1d. Figure 5 shows the size distribution of precipitates formed in $\mathrm{Cu}-0.8$ at. $\% \mathrm{Fe}-0.2$ at. \% Co. These distributions fall into two types, with narrow and broad peaks respectively. The size distributions in specimens annealed for periods up to 2000 min show a narrow distribution with a
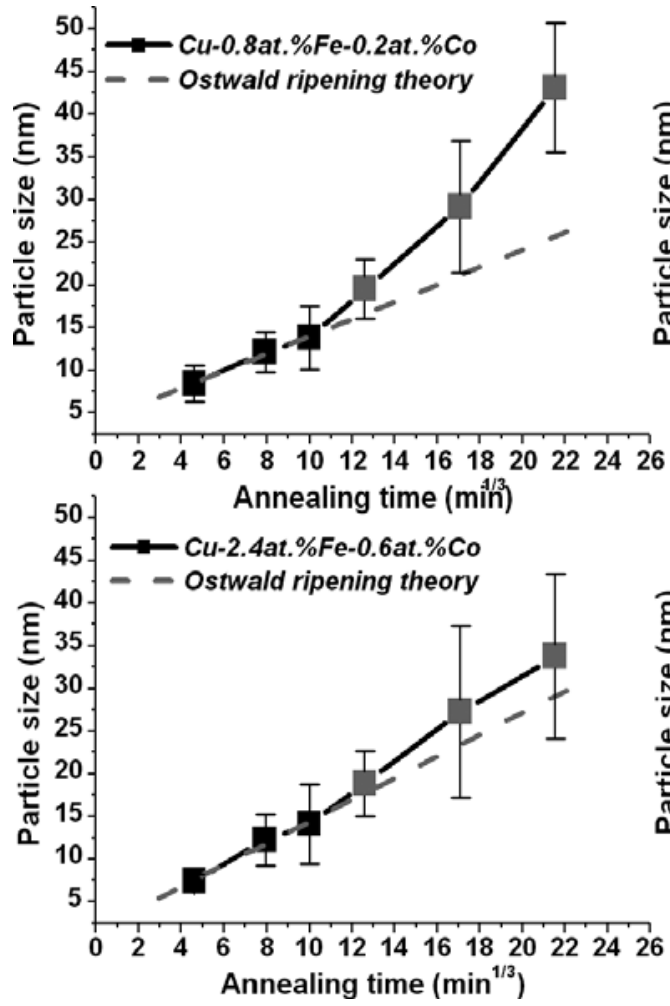

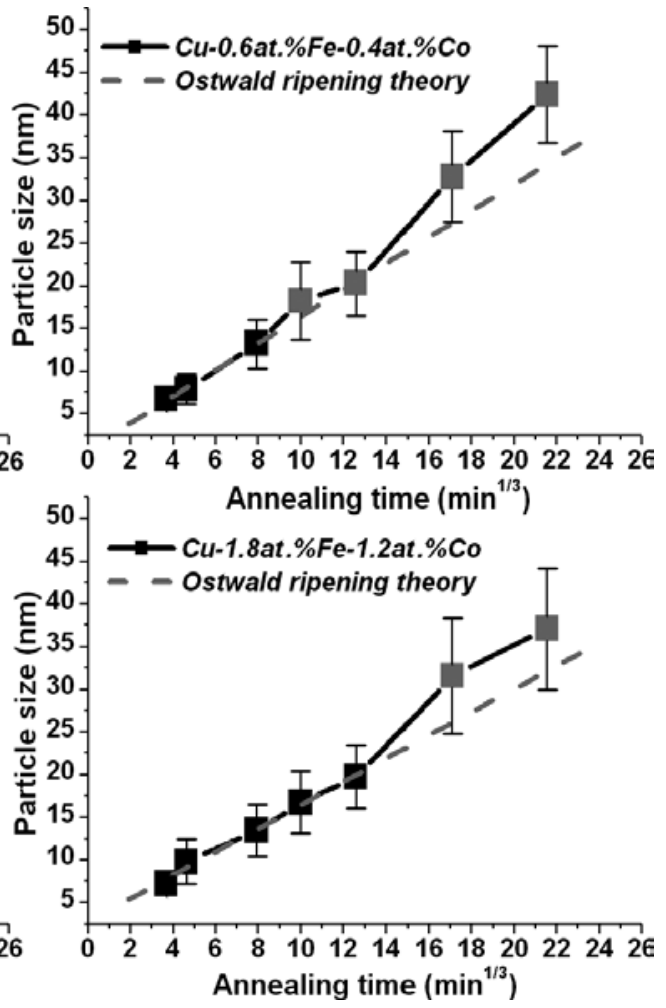

Fig. 4. The mean size of $\mathrm{Fe}-\mathrm{Co}$ precipitates vs one-third power annealing time for (a) $\mathrm{Cu}$ 0.8 at. $\% \mathrm{Fe}-0.2$ at. $\% \mathrm{Co}$, (b) $\mathrm{Cu}-$ 0.6 at. $\% \mathrm{Fe}-0.4$ at. $\% \mathrm{Co}$, (c) $\mathrm{Cu}-$ 2.4 at. $\% \mathrm{Fe}-0.6$ at.\% Co, and (d) $\mathrm{Cu}-1.8$ at.\% Fe-1.2 at.\% Co. 

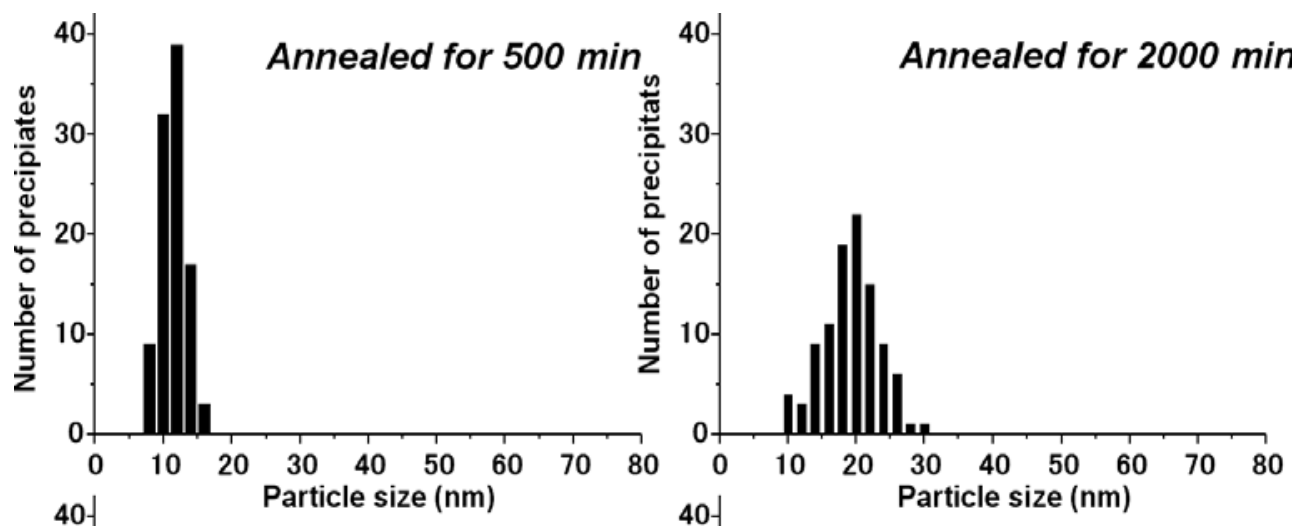

Fig. 5. The size distributions of the precipitates formed in $\mathrm{Cu}$ 0.8 at. $\% \mathrm{Fe}-0.2$ at. \% $\mathrm{Co}$ aged at

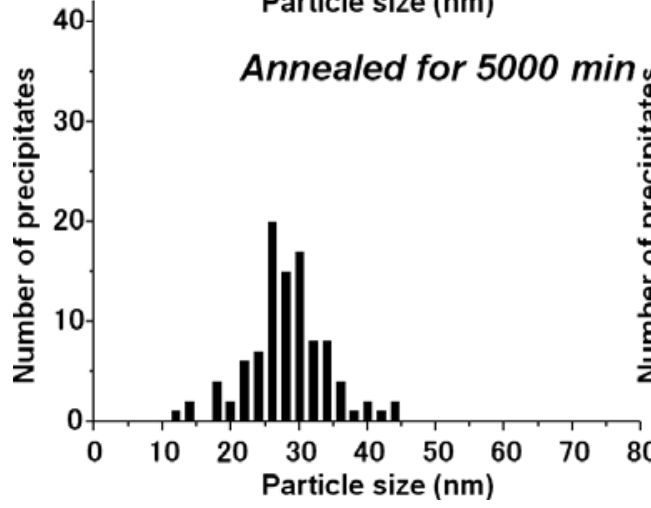

Annealed for $10000 \mathrm{~min}$ $873 \mathrm{~K}$.

sharp peak. However, in specimens annealed for more than 5000 min there are broader distributions in size. The same trends have been reported in a $\mathrm{Cu}-\mathrm{Co}$ alloy [6]. Broader size distributions reflect the transformation of $\mathrm{Fe}-\mathrm{Co}$ precipitates from fcc into bcc.

\subsection{The magnetic properties of $\mathrm{Cu}-\mathrm{Fe}-\mathrm{Co}$ alloys}

In the previous section, we described how the microstructures of $\mathrm{Cu}-\mathrm{Fe}-\mathrm{Co}$ alloys evolve with annealing time. Since the magnetic properties of the precipitates depend on their microstructure, we examined the magnetic properties of the specimens using a SQUID magnetometer, measuring

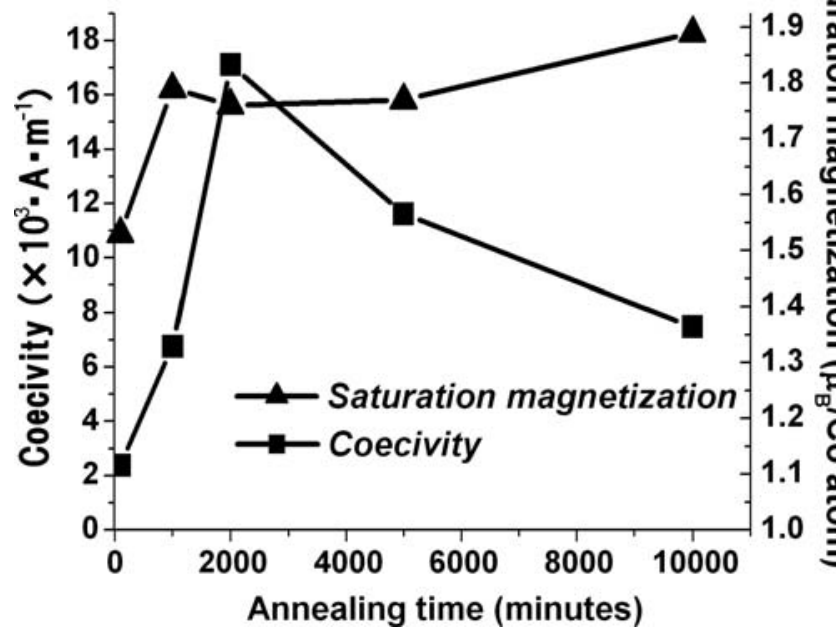

Fig. 6. The change of saturation magnetization and coercive force of $\mathrm{Cu}-0.8$ at.\% $\mathrm{Fe}-0.2$ at.\% Co with annealing time. the hysteresis curves of the specimens at each stage of the annealing process. Figure 6 shows the saturation magnetization and coercivity of $\mathrm{Cu}-0.8$ at. $\% \mathrm{Fe}-0.2$ at. $\%$ Co. The saturation magnetization increased with annealing time at the early stage of the precipitation process. The saturated curve attained a maximum value of approximately $1.8\left(\mu_{\mathrm{B}} /\right.$ atom) at $1000 \mathrm{~min}$, and the saturation remained constant up to $10000 \mathrm{~min}$. This fact suggests that precipitation has almost been completed within the early stage of the annealing process. This is also consistent with the TEM measurement of volume fraction of precipitates, shown in Fig. 3.

Few close studies have been performed so far on the relationship of the microstructure and the coercive force of materials containing nano-scale magnetic particles. The present measurements revealed that the coercivity first increased, reached a maximum value of $1.711 \times 10^{4} \mathrm{~A} \cdot \mathrm{m}^{-1}(215 \mathrm{Oe})$ at an annealing time of $2000 \mathrm{~min}$, and then decreased. As seen in Fig. 1c, at an annealing time of 2000 min particles were assembled and linearly aligned, whereas at an earlier stage of annealing they were randomly distributed in the matrix. At this stage, the separations of paired particles became smaller. Based on the previous work by Luborsky and Paine [15], the increase in the coercive force suggests that precipitates consist of single magnetic domains at the early stage of annealing process. In this case it is expected that the peak of the coercivity occurs as a result of magnetic interaction between paired particles. The reason that the coercive force decreased after annealing for more than $2000 \mathrm{~min}$ is not fully understood, but it may suggest that multi-domain precipitates are formed. It is expected that the coercivity is dominated by the mobility of magnetic domain walls in bulk materials, and spin rotation is much more easily performed by domain-wall motion. One possible interpretation is that the transformation from single- to multiple-domain particles is associated with the structural transformation from fcc to bcc. 
N. Wada et al.: The relationship between the microstructure and the magnetic properties of nano-scale magnetic particles

In order to test this hypothesis, in future studies of $\mathrm{Cu}-$ $\mathrm{Fe}-\mathrm{Co}$ alloys we intend to apply Lorentz microscopy, which is capable of providing information on the magnetization of individual particles.

\section{Conclusion}

We have investigated the relationship between the microstructure and magnetic properties of $\mathrm{Cu}-\mathrm{Fe}-\mathrm{Co}$ alloys using TEM and SQUID magnetometry. The present investigation revealed:

1. At an early stage of evolution, particles were spherical and had an fcc structure, inherited from the $\mathrm{Cu}$ matrix. Particles were initially located randomly but at a somewhat later annealing stage a linear alignment of particles was found.

2. At a late stage of annealing, particles lost their coherency to the matrix.

3. The growth rate of incoherent particles was greater than that of coherent particles.

4. As the transformation of microstructure occurred, the coercivity of particles reduced.

We wish to thank Dr. Masaki Takeguchi of Advanced Electron Microscopy Group, NIMS, Japan for his kind assistance in TEM observations. This work was supported in part by Grants-in-Aid for Scientific Research from JSPS of Japan (No.18560643).

\section{References}

[1] A.E. Berkowitz, J.R. Mitchell, M.J. Carey, A.P. Young, S. Zhang, F.E. Spada, F.T. Parkar, A. Hutten, G. Thomas: Phys. Rev. B 68 (1992) 3745.

PMid:10045786; DOI:10.1103/PhysRevLett.68.3745

[2] Y. Tsunoda: J. Phys. Cond. Matt. 1 (1989) 10427. DOI:10.1088/0953-8984/1/51/015

[3] H. Kubo, V. Uchimoto, K. Shimizu: Metal Schi. J. 9 (1985) 153.

[4] S.C. Abrahams: Phys. Rev. 127 (1962) 2052. DOI:10.1103/PhysRev.127.2052

[5] M. Takeda, K. Inukai, N. Suzuki, G. Shinohara, H. Hashimoto: Phys. Stat. Sol. (a) 158 (1996) 39. DOI: $10.1002 /$ pssa.2211580106

[6] M. Takeda, N. Suzuki, G. Shinohara, T. Endo, J. Van Landuyt: Phys. Stat. Sol. (a) 168 (1998) 27. DOI:10.1002/(SICI)1521-396X(199807)168:1<27:: AID-PSSA27>3.0.CO;2-S

[7] M. Takeda, H. Yamada, S. Yoshida, T. Endo, J. Van Landuyt: Phys. Stat. Sol. (a) 198 (2003) 436. DOI:10.1002/pssa.200306634

[8] M. Shiga, M. Yamamoto: J. Phys. Condens. Matter 13 (2001) 6359. DOI:10.1088/0953-8984/13/29/306
[9] T. Fujita, S. Nishimura, T. Fujinami, K. Kaneko, Z. Horita, D.J. Smith: Mater. Sci. Eng. A 417 (2006) 149. DOI:10.1016/j.msea.2005.11.008

[10] S. Onaka, N. Kobayashi, T. Fujita, M. Kato: Mater. Sci. Eng. A 347 (2003) 42. DOI:10.1016/S0921-5093(02)00559-2

[11] J.D. Livingston: Trans. Amer. Inst. Min. Metall. 215 (1959) 566.

[12] A.J. Ardell, R.B. Nicholson: J. Phys. Chem. Solids 27 (1966) 1793. DOI:10.1016/0022-3697(66)90110-7

[13] S. Iwamura, Y. Miura: Acta Mater. 52 (2004) 591. DOI:10.1016/j.actamat.2003.09.042

[14] N. Kuwano, S. Matsumira, H. Nakagawa, M. Watari, Y. Tomokiyo, K. Oki: in Proc. Int. Conf. on Martensitic Transformation, ICOMAT-86, 355. Japan Inst. Of Metal, Sendai, Japan (1986) 355

[15] F.E. Luborsky, T.O. Paine: J. Appl. Phys. 31 (1960) 68S. DOI: $10.1063 / 1.1984606$

[16] C. Watanabe, D. Watnabe R. Monzen: J. Mater. Sci. 43 (2008) 3817. DOI:10.1007/s10853-007-2290-6

(Received September 26, 2008; accepted August 3, 2009)

\section{Bibliography}

DOI $10.3139 / 146.110287$

Int. J. Mat. Res. (formerly Z. Metallkd.)

101 (2010) 3; page 356-360

(C) Carl Hanser Verlag GmbH \& Co. KG

ISSN 1862-5282

\section{Correspondence address}

Associate Prof. Mahoto Takeda

Department of Mechanical Engineering and

Materials Science (SEISAN), Yokohama National University

79-5 Tokiwadai Hodogaya, Yokohama 240-8501, Japan

Tel.: +81453393855

Fax: +81453393855

E-mail: t1k4d1@ynu.ac.jp

You will find the article and additional material by entering the document number MK110287 on our website at www.ijmr.de 